\title{
Physicochemical characterization of Moringa oleifera's shells as biosorbent for pharmaceuticals biosorption
}

\author{
De Olivera $\mathrm{A}^{* \dagger}$, Kreutz $\mathrm{C} \S$ and Martins $\mathrm{R} \dagger$ \\ *National University of Misiones (UNaM), Misiones, Argentina. §Federal University of \\ Technology-Paraná, Campo Mourão, Brazil. $\dagger$ Polytechnic Institute of Bragança (IPB), \\ Bragança and LSRE-LCM, FEUP, Porto, Portugal.
}

\begin{abstract}
The pharmaceuticals as emerging contaminants have become one of the most controversial environmental issues at global scale. Over the years, the presence of antibiotics and anti-inflammatory drugs inside rivers, lakes, and even inside drinking water streams has increased. The wastewater treatment plants (WWTPs) lack the necessary technology to remove concentrations between the range ng/l-mg/l and therefore, the need to develop new methods able to remove contaminants in an effective, low cost and environmental friendly way arises. The present work is focused on studying the potential adsorption capacity of Moringa oleifera (MO) to remove Diclofenac (DCF) and Oxytetracycline (OTC) from wastewater. Through different experiences, it was possible to characterizes the main functional groups of $\mathrm{MO}$ and determine the principal responsible of the biosorption process.
\end{abstract}

Keywords. Pharmaceuticals, Diclofenac, Oxytetracycline, biosorption, Moringa oleífera.

Introduction. Biosorption is an adsorption process that uses biological material as "biosorbent" (1). Moringa oleifera (MO), the best-known variety of the genus Moringacea, is a tree native to the southern foothills of the Himalayas, the north of India, Bangladesh, Afghanistan and Pakistan (2). It is considered one the most famous plants worldwide. So far, it is known that it has application in the areas of human and animal nutrition (3), medicinal use (4) and wastewater treatment (5). The objective of this work is to determine the main functional groups of the MO shells before and after the biosorption process of DCF and OTC.

\section{Methods and materials}

The Moringa oleifera (MO) shells were taken from Luanda, Angola, Africa. The pharmaceuticals were Oxytetracycline hydrochloride (>95\% crystalline) and Diclofenac Sodium, both obtained by Sigma-Aldrich Company. In all the experiences, it was prepared $1 \mathrm{mg} / \mathrm{l}$ solution, diluted with distilled water. 


\section{Biosorbent preparation}

MO's shells were dried in oven at $30^{\circ} \mathrm{C}$ for one day and pulverized into powder through IKA A11 basic analytical mill. Moringa powder was separated according to the size of the grain through a series of sieves with different diameters $(0,425 \mu \mathrm{m}, 0,250 \mu \mathrm{m}, 0,106 \mu \mathrm{m}, 0,075 \mu \mathrm{m}$ and lower than $0,075 \mu \mathrm{m}$ ) ordered in column. The experiences were done with the granulometry $0,106<\mu \mathrm{m}<0,205$.

\section{Characterization of MO by FTIR}

Fourier transform infrared spectroscopy (FTIR) was performed to determine the functional groups present in the $\mathrm{MO}$ and the effect of the interaction between the pharmaceuticals and the biosorbent. For this analysis, it was prepared $\mathrm{KBr}$ pellets, through the use of the SPECAC Hydraulic Press and it was used the UATR Two Perkin Elmer Spectrum FT-IR C112095. The transmittance spectra were obtained in a wavelength range between $4000-450 \mathrm{~cm}^{-1}$ and with a resolution of $4 \mathrm{~cm}^{-1}$. The data were processed using Perkin Elmer Spectrum IR Software Version 10.6.1.

\section{Results and discussion}

The Erro! Fonte de referência não encontrada.Figure 1shows the presence of many functional groups, indicating the complex nature of Moringa oleifera shells.

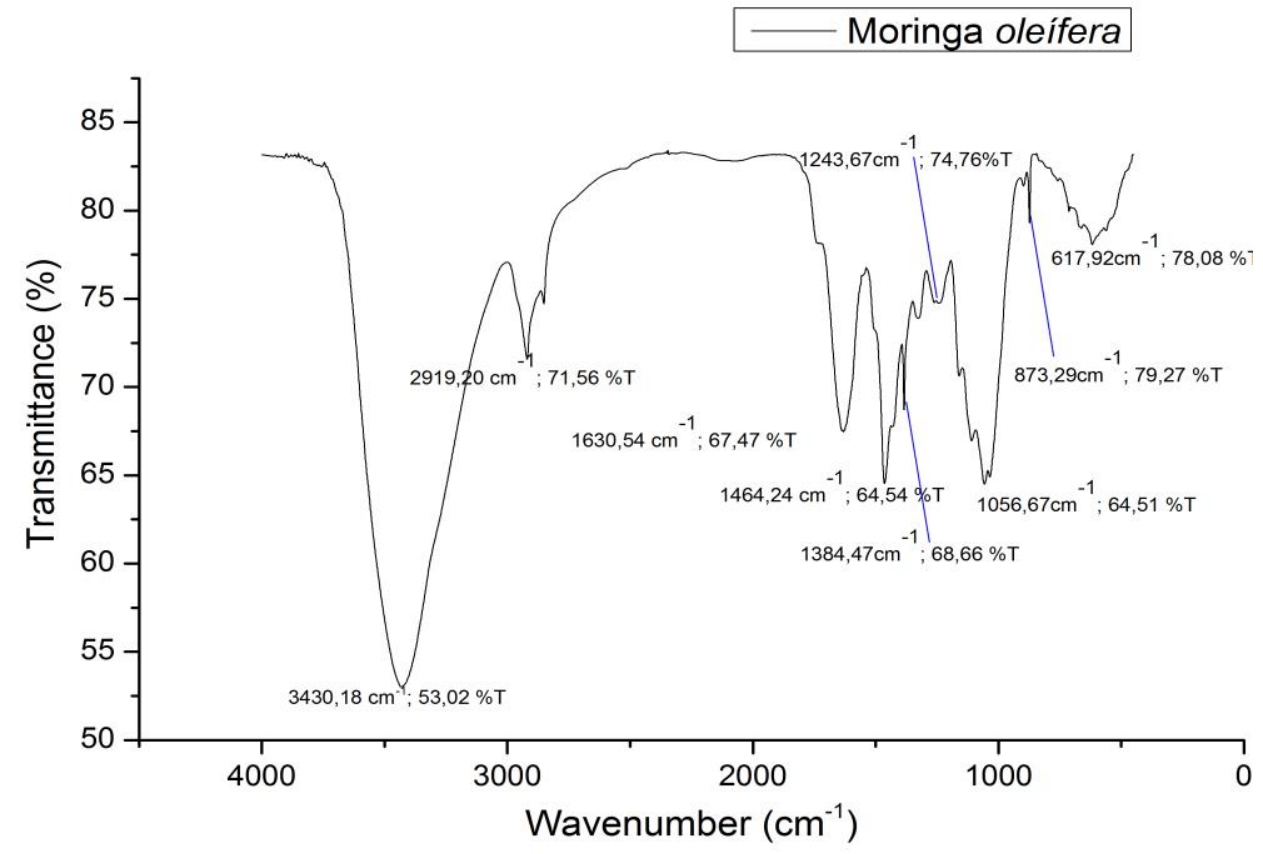

Figure 1. Principal functional groups of Moringa oleífera 
A strong peak at $3430 \mathrm{~cm}^{-1}$ indicates the presence of the hydroxyl group (-OH) which could belong to the proteins, fatty acids, carbohydrates and phenolic compounds $(6,7,8)$. The peak at $2920 \mathrm{~cm}^{-1}$ indicates the presence of $-\mathrm{C}-\mathrm{H}$ bond of the $\mathrm{CH}_{2}$ group, which could be related to the cellulose structure. The peak at $1630 \mathrm{~cm}^{-1}$ is due to the carbonyl group $(-\mathrm{C}=\mathrm{O})$ that could belong to the primary or secondary Amide compounds $\left(\mathrm{NH}_{2} \mathrm{CO}\right)$. The band at $1464 \mathrm{~cm}^{-1}$ corresponds to the $-\mathrm{C}=\mathrm{C}$ of Aromatics compounds. In the region of $1384-1243 \mathrm{~cm}^{-1}$, it is found a series of weak peaks that could correspond to the presence of carboxylic acids. The strongest band is near to the wavelength of $1056 \mathrm{~cm}^{-1}$ and is attributed to the $-\mathrm{C}-\mathrm{O}$ bond, as a prove of the presence of phenols compounds, carboxylic acids and also showing the lignocellulosic structure of the biosorbent (9).At least, the weak bands between $873-618 \mathrm{~cm}^{-1}$ could correspond to the $-\mathrm{C}-\mathrm{H}$ bond of aromatics compounds.

From

Figure 2 can be seen that after the adsorption process, the peak at $3430 \mathrm{~cm}^{-1}$, which represents the $-\mathrm{OH}$ - group, the band at $1637 \mathrm{~cm}^{-1}(-\mathrm{C}=\mathrm{O})$ and the peak at $1459 \mathrm{~cm}^{-1}(-\mathrm{C}=\mathrm{C})$ have been changed. These changes indicate that the hydroxyl, carbonyl and aromatic groups are the responsible for the DCF removal. Also that could generate a strong interaction between the negatives charges of the groups of the adsorbent with the positives charges, as for example of the amine group, of the anti-inflammatory.

It can be observed two new peaks, the first one at $610 \mathrm{~cm}^{-1}$, which belongs to the aromatic group $(-\mathrm{C}-\mathrm{Cl})$ of DCF and another one at $1506 \mathrm{~cm}^{-1}$ which confirms the presence of its aromatic ring (10).

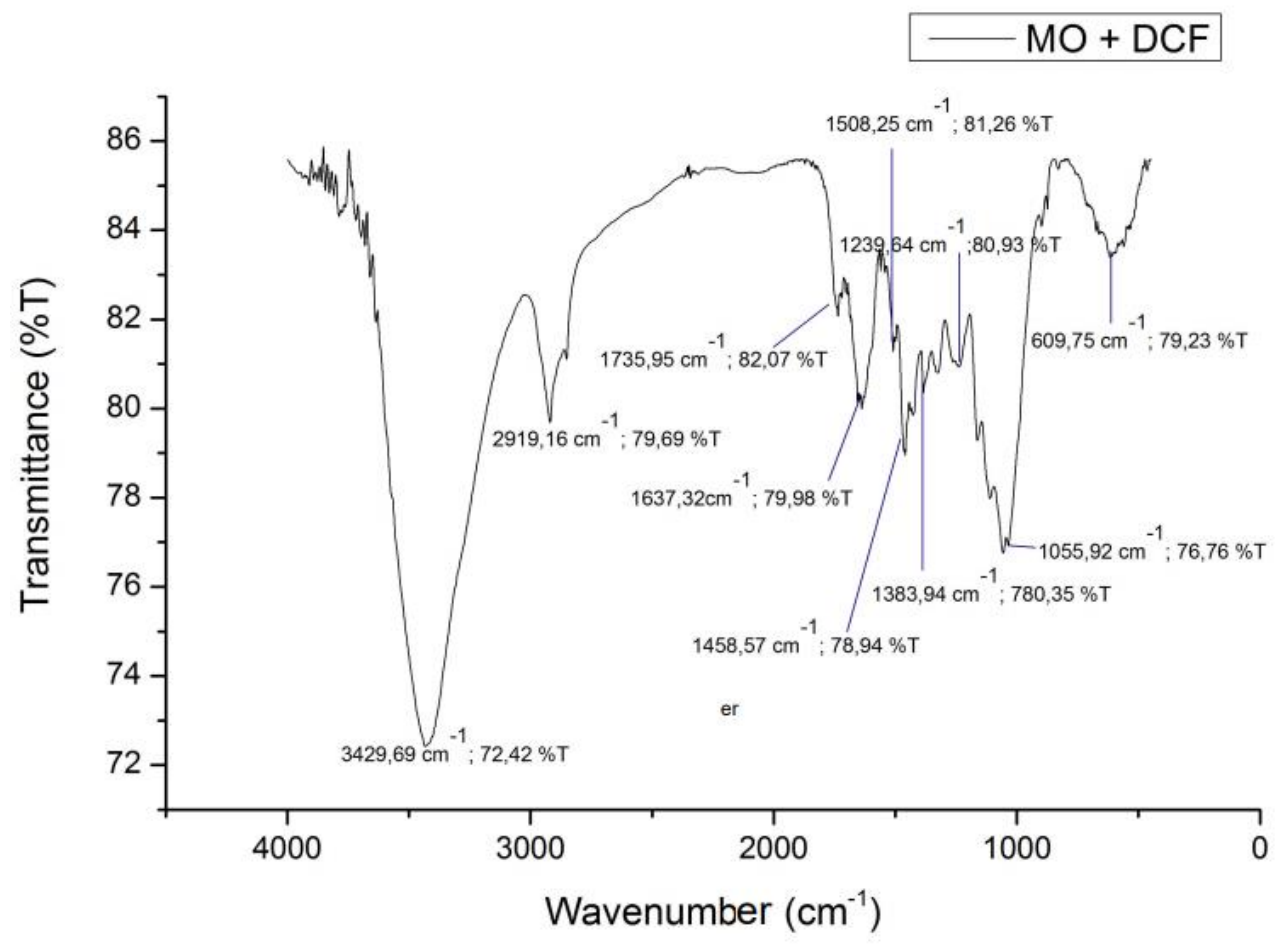


Figure 2.Moringa oleifera shells composition after adsorption process of DCF from water.

The Figure 3 illustrates the results of the adsorption process of Oxytetracycline solution. Knowing the complex composition of the antibiotic (amides, carbonyl, amines, hydroxyl and aromatic groups), the main differences can be seen at the following peaks: $3435 \mathrm{~cm}^{-1}(-\mathrm{OH})$, $1633 \mathrm{~cm}^{-1}(-\mathrm{C}=\mathrm{O}), 1465 \mathrm{~cm}^{-1}(-\mathrm{C}=\mathrm{C}), 1260 \mathrm{~cm}^{-1}$ and $1055 \mathrm{~cm}^{-1}$ of carboxyl acids, indicating that the responsible of the adsorption, also in this case, are the hydroxyl, carbonyl and aromatic groups.

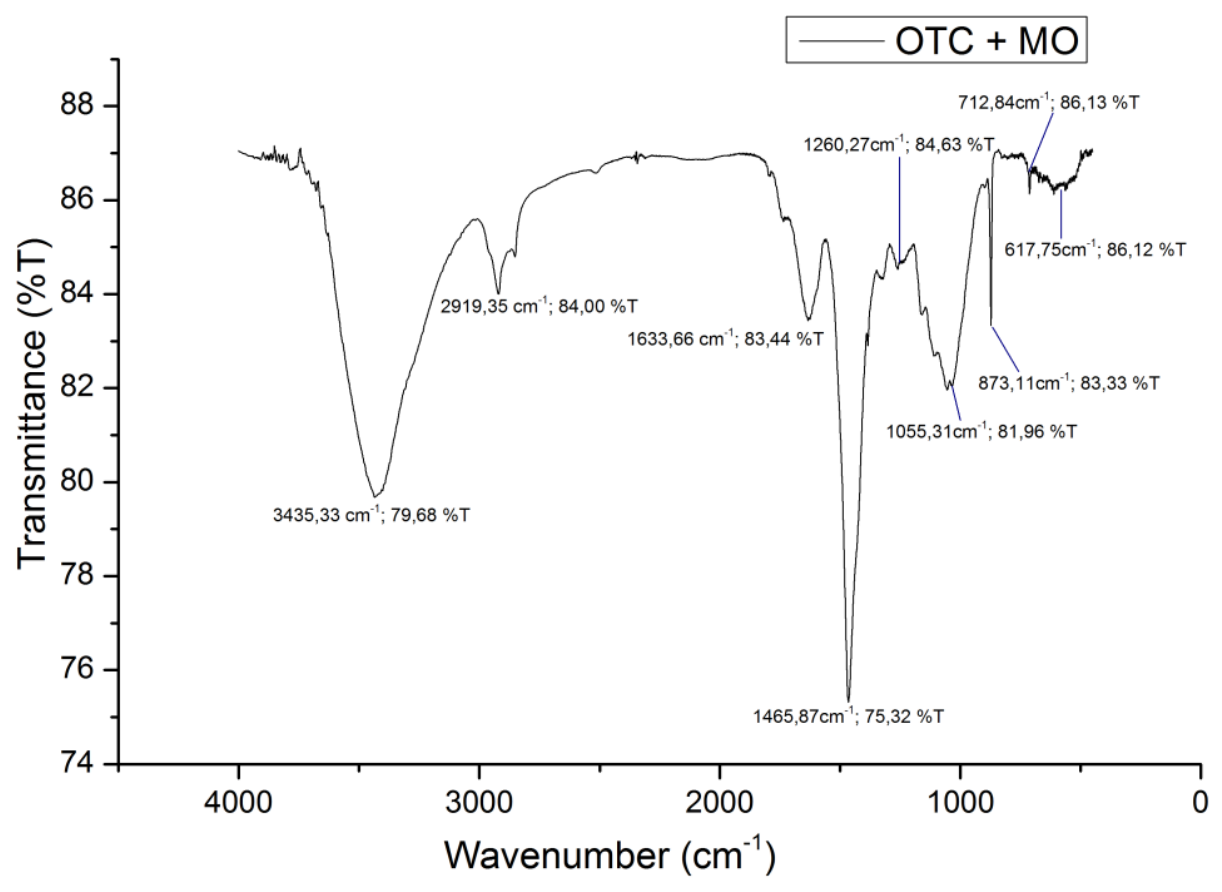

Figure 3.Moringa oleifera shells composition after adsorption process of OTC from water.

The lower absorption at $3435 \mathrm{~cm}^{-1}$ could be related to hydrogen bonding between the functional groups of the adsorbent and the antibiotic. The peak at $712 \mathrm{~cm}^{-1}$ could indicate the complex formation between the OTC and the adsorbent or also the presence of aromatic group of the antibiotic (11).

Conclusion. By FTIR analysis, it is known that Moringa oleifera shells present a complex nature and a huge variety of functional groups, such as hydroxyl (-OH), $-\mathrm{CH}$ bonds, carbonyl group (- 
$\mathrm{C}=\mathrm{O}$ ), $-\mathrm{C}=\mathrm{C}$ of aromatic compounds, carboxylic acids, amines, amides and phenol compounds. After DCF and OTC adsorption processes. It was possible to determine that, in both cases, the possible responsible are the hydroxyl $(-\mathrm{OH})$, carbonyl $(-\mathrm{C}=\mathrm{O})$ and aromatic groups $(-\mathrm{C}=\mathrm{C})$.

Acknowledgments. This work was financially supported by the Associate Laboratory LSRELCM - UID/EQU/50020/2019 - funded by national funds of Portugal through FCT/MCTES (PIDDAC).

Disclosure. The authors report no conflicts of interest in this work.

\section{References}

(1) Lagos Estrella, A. (2017). Adsorción de cadmio, hierro y plomo en agua artificial utilizando Moringa oleifera Lam (Ingeniería Química). Universidad San Francisco de Quito USFQ. Colegio de Ciencias e Ingenierías.

(2) Perez, A., (2010). Characteristics and potential of Moringa oleifera, Lamark. An alternative for animal feeding. Pastos Y Forrajes, 33(4).

(3) Martín, C., (2013). Potenciales aplicaciones de Moringa oleifera. Una revisión crítica. Pastos Y Forrajes, 36 (2), pp. 137-149.

(4) Anwar, F., Latif, S., Ashraf, M., \& Gilani, A. (2006). Moringa oleífera: a food plant with multiple medicinal uses. Phytotherapy Research, 21(1), 17-25.

(5) Foidl N., Makkar H. and Becker K. (2001). The Potential of Moringa oleifera for agricultural and industrial uses. Moringa oleifera Webpage, 2.

(6) Kawo, A., Abdullahi, B., Halilu, A., Gaiya, Z., Dabai, M., \& Dakare, M. (2009). Preliminary phytochemical screening, proximate and elemental composition of Moringa oleifera lam seed powder. Bayero Journal of Pure and Applied Sciences, 2(1), 96-100.

(7) Rashid, U., Anwar, F., Moser, B. R., \& Knothe, G. (2008). Moringa oleifera oil: a possible source of biodiesel. Bioresource technology, 99(17), 8175-8179.

(8) Sodamade, A., Bolaji, O. S., \& Adeboye, O. O. (2013). Proximate analysis, mineral contents and functional properties of Moringa oleifera leaf protein concentrate. IOSR Journal of Applied Chemistry, 4(6), 47-51.

(9) Araujo, L., (2018). Moringa oleifera biomass residue for the removal of pharmaceuticals from water. Journal Of Environmental Chemical Engineering, 6(6), pp. 7192-7199.

(10) Karuna, U., (2016). Preparation and Evaluation Of Chitosan Succinate Pellets Using Extrusion-Spheronization Technology: Processing And In Vitro Characterization. Turkish Journal of Pharmaceutical Science. 13.pp. 68-86.

(11) Harja, M., Ciobanu, G. (2018). Studies on adsorption of oxytetracycline from aqueous solutions onto hydroxyapatite. Science Of The Total Environment, 628-629, 36-43. 